\title{
Assessing planning approaches by watershed streamflow modeling: Case study of The Woodlands; Texas
}

\author{
Bo Yang ${ }^{\mathrm{a}, *}$, Ming-Han Li ${ }^{\mathrm{b}, 1}$ \\ ${ }^{a}$ Department of Landscape Architecture and Environmental Planning, Utah State University, 4005 Old Main Hill, Logan, UT 84322-4005, USA \\ ${ }^{\mathrm{b}}$ Department of Landscape Architecture and Urban Planning, College of Architecture, Texas AEMM University, College Station, TX 77843-3137, USA
}

\section{A R T I C L E I N F O}

\section{Article history:}

Received 11 November 2009

Received in revised form 19 August 2010

Accepted 20 August 2010

Available online 16 September 2010

\section{Keywords:}

Ian McHarg

GIS

Ecological planning

Flood mitigation

Soil and water assessment tool

Kinematic runoff and erosion model

\begin{abstract}
A B S T R A C T
The Woodlands, Texas, is well known as a town created following Ian McHarg's ecological planning approach that uses soil permeability to coordinate development densities and land use. Very few studies have quantitatively measured the effect of this planning approach on stormwater management. In this study, watershed stream flow modeling was conducted to assess five hypothetical land use scenarios. These scenarios were compared with The Woodlands' 2005 condition using the Automated Geospatial Watershed Assessment (AGWA) tool that simulates watershed long-term stream flow and peak discharges during single storms. The objectives are to: (1) assess The Woodlands development conditions during 1974-2005 on whether land use locations are based on soil infiltration capacities and (2) compare stormwater runoff generated in different planning approaches (conventional low-density, clustered high-density, and The Woodlands approaches) using watershed streamflow modeling. Stream flow data from U.S. Geological Survey gauge stations were used for AGWA model calibration and validation. The result of percent development on different soil types indicates that McHarg's approach was more closely followed before 1997. After The Woodlands' ownership was sold in 1997, later developments did not follow McHarg's approach. The departure from McHarg's approach after 1997 is also reflected in the stream flow simulation results. The 2005 observed stream flow volume is around $50 \%$ higher than that of the simulated condition that would result if McHarg's approach was kept. Overall, McHarg's approach using soil permeability to coordinate development densities and land use is effective in mitigating flood, especially during intense storm events.
\end{abstract}

Published by Elsevier B.V.

\section{Introduction}

Urbanization-induced hydrological alterations have been discussed extensively in the literature (Arnold and Gibbons, 1996; Paul and Meyer, 2001). Urban development reduces the infiltration capacity of the natural landscape, concentrates stormwater flows, and results in water quality and quantity problems in receiving water bodies (Schueler, 1994). For the last two decades, imperviousness continues to be the most common measure to quantify the effect of urban development on watershed hydrological conditions (Schueler, 1994; Arnold and Gibbons, 1996). Furthermore, not only the quantity but also the spatial configuration of imperviousness influences watershed outflows (Hammer, 1972; Rogers and DeFee, 2005). Alberti and Marzluff (2004) and Alberti et al. (2007) suggested both urban form and land cover pattern can be viable measures for the changes of the hydrological regime.

\footnotetext{
* Corresponding author. Tel.: +1 435797 0506; fax: +1 4357970503.

E-mail addresses: bo.yang@usu.edu (B. Yang), minghan@tamu.edu (M.-H. Li).

1 Tel.: +1979 8457571 .
}

The major urban development project of the past century in the United States has been the development of suburban communities. Conventional community development practice imposes a homogeneous hardscape pattern on the natural landscape, giving little consideration to advantageous drainage opportunities. Traditional drainage designs aim to remove stormwater as quickly as possible, thus creating a flooding problem downstream (Ferguson, 1998). The current mitigation practice of using various detention and retention basins to arrest excessive runoff after storms is hindered in dense urban settings (Ellis and Marsalek, 1996). In addition, if the basin is located inappropriately, it exacerbates flooding (Perez-Pedini et al., 2005). Prince George's County, Maryland, piloted a more comprehensive hydrological mitigation approach, called "low impact development" (LID) (Prince George's County, 1999). The LID concept was further advocated by the U.S. Environmental Protection Agency (USEPA, 2000). LID suggests development policies and urban guidelines and also combines a number of techniques, including storing, infiltrating, evaporating, and releasing runoff slowly, at a rate not exceeding that of the predevelopment condition (USEPA, 2000). 


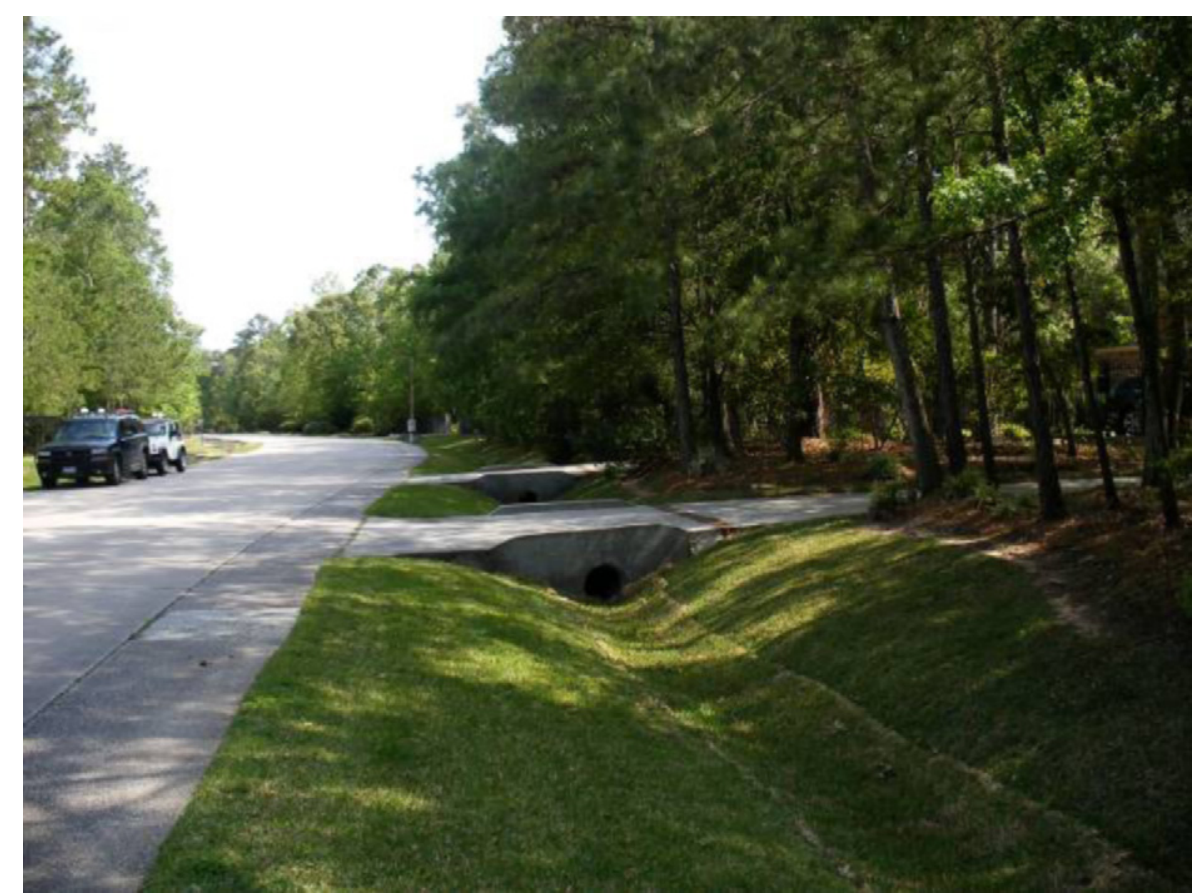

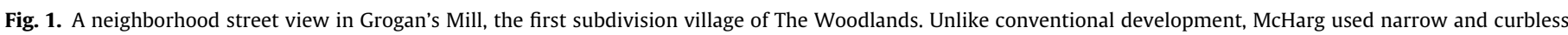
streets, with open surface drainage, mandated to preserve the original vegetation after development.

A noteworthy function of LID techniques is infiltration. Infiltration is arguably the most viable method to lower runoff volume, as suggested by studies prior to the LID concept and echoed by current studies (Ferguson, 1995; Echols, 2008). The Woodlands, Texas, is one of the precursors that applied the LID concept in community development in the 1970s (Yang and Li, 2010). George Mitchell, a self-made oil and real estate businessman and an environmentally conscious developer, launched this project in a lush loblolly pine (Pinus taeda) forest $50 \mathrm{~km}$ north of Houston (Morgan and King, 1987). What The Woodlands is most renowned for is perhaps being the first master-planned community that employed Ian McHarg's ecological planning approach (McHarg and Sutton, 1975; Forsyth, 2002; Kim and Ellis, 2009) (Fig. 1 and Fig. 2). Development of The Woodlands is expected to be substantially completed around 2015 (Galatas and Barlow, 2004). The 2006 population was 83,884, and it is projected to be 111,740 by 2011 (The Woodlands Development Company, 2007).

McHarg's ecological planning approach was to determine building densities and land use based on the hydrological properties of the soil-that is, permeability. This concept was achieved by pre-

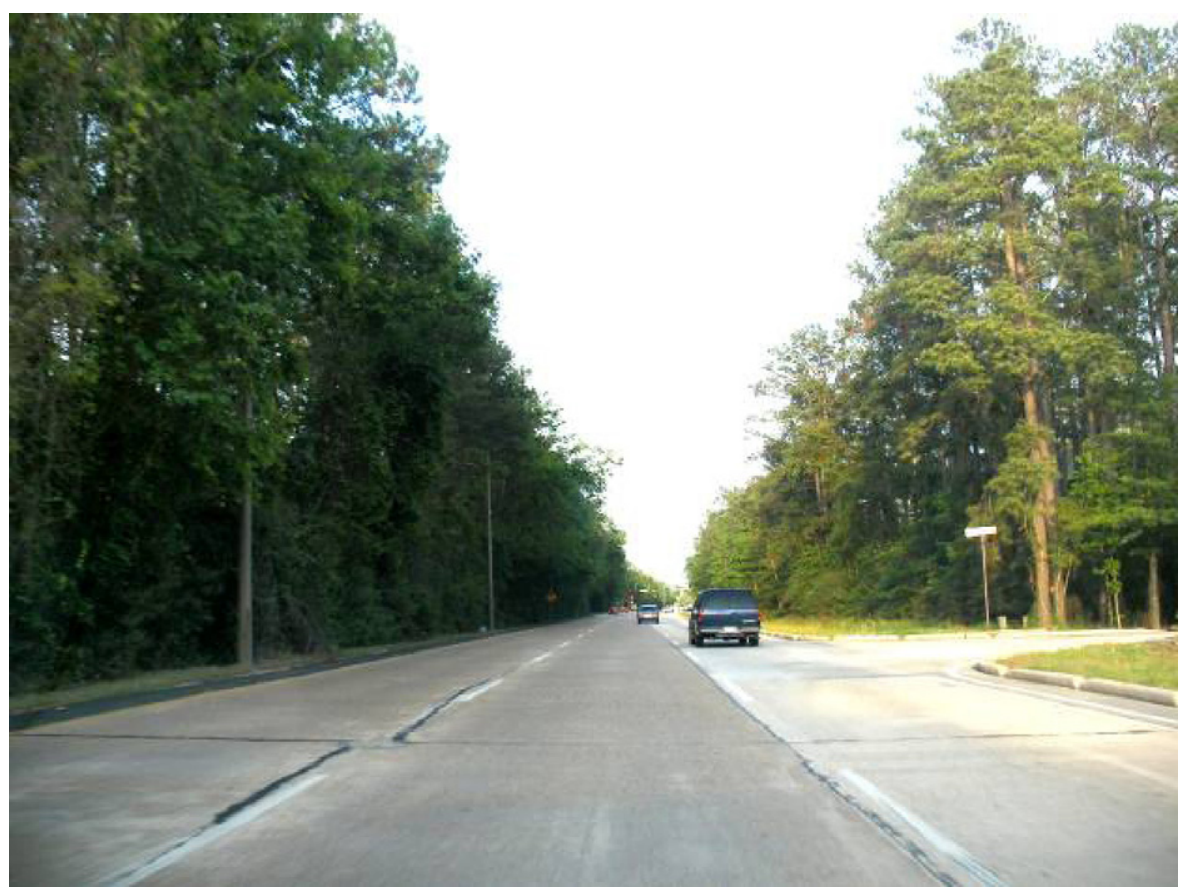

Fig. 2. A street view of The Woodlands Parkway. Commercial and residential buildings are hidden by the tree mask. 
serving land with high soil permeability as open space and using land with low soil permeability for commercial or residential developments (McHarg, 1996). Despite the lack of scientific evaluation, this ecological planning approach is regarded as successful based on extreme storm events. The Woodlands survived the 100-year storms in 1979 and 1994 with little property damage, while Houston, located $50 \mathrm{~km}$ to the south, was severely flooded in both events (Girling and Kellett, 2005).

However, McHarg's concept was subjected to several changes during the course of development over the past three decades. The concept was followed in the first suburban village (Village of Grogan's Mill) and part of the second village (Village of Panther Creek) of The Woodlands but was adjusted to meet the homeowners' preferences of conventional suburbs in the later villages (Galatas and Barlow, 2004). A significant setback from the original McHarg plan occurred in 1985, although the spirit of the "ecological plan" remained in the community mission statement (Girling and Helphand, 1994). The year of 1997 witnessed a further adjustment to the plan when George Mitchell sold The Woodlands to Crescent Real Estate Equities and Morgan Stanley Real Estate Fund II (ownership 1997-2003), after which development sped up and did not follow McHarg's concept (Galatas and Barlow, 2004). After 1997, the pace of construction accelerated and much of the forest preserve land was converted into residential and commercial developments (Haut, 2006). More pronounced environmental impacts emerged-The Woodlands was flooded in 2000 (NOAA, 2000) and again in 2008 as a result of Hurricane Ike (Madere, 2008). During Hurricane Ike, western Woodlands, containing villages developed after 1997, was particularly hard-hit. However, the early villages developed following McHarg's approach remained safe places (Madere, 2008).

McHarg's ecological planning approach intuitively suggests its effectiveness in mitigating development impacts on stormwater. However, for the past three decades, little study has been conducted to evaluate the effectiveness of this approach. The objectives of this study are to: (1) assess The Woodlands development conditions during 1974-2005 on whether land use locations are based on soil infiltration capacities and (2) compare stormwater runoff generated in different planning approaches (conventional lowdensity, clustered high-density, and The Woodlands approaches) using watershed streamflow modeling. Five "what-if" land use scenarios of The Woodlands that reflect different planning approaches were created for watershed simulation. Furthermore, development was designated onto different soil types (e.g., sandy or clay soils) to assess McHarg's concept. A homogeneous forest land use scenario served as the baseline condition to represent The Woodlands prior to any development (Soil Conservation Service, 1972). Scenarios were compared by using the Automated Geospatial Watershed Assessment (AGWA) tool that simulates stream flow (Miller et al., 2007).

\section{Materials and methods}

\subsection{Study site}

The study area is the Panther Creek watershed, in which the majority of The Woodlands is located. Fig. 3 presents development conditions in the Panther Creek watershed. The watershed lies completely within Montgomery County, Texas, and is a subwatershed of the Spring Creek watershed, whose U.S. Geological Survey (USGS) hydrological unit code is 12040102. Interstate Highway 45 runs parallel to The Woodlands to the east and is a major transportation corridor connecting Houston ( $50 \mathrm{~km}$ away) to the south and Dallas/Fort Worth (340 km away) to the north.
The Panther Creek watershed boundary was delineated using the outlet located at the confluence of Panther Creek and Spring Creek (Bedient et al., 1985). The drainage area of the watershed is $94.2 \mathrm{~km}^{2}$. The linear length of the watershed is approximately $37 \mathrm{~km}$ from the headwater to the outlet. The average slope of the watershed is less than $1 \%$. There are two USGS gauge stations on the main channel of Panther Creek: station No. 08068450 and station No. 08068400 (Fig. 3). The average annual rainfall in this region is $840 \mathrm{~mm}$. However, annual hurricane visitation often generates intense rainfall in single events, which sometimes causes widespread flooding.

\subsection{Data}

Stream flow data from both USGS gauge stations on Panther Creek during the water years of 1999-2006 were used for the AGWA hydrological model calibration and validation analysis. A water year is from October 1 of the previous year to September 30 of the following year (e.g., water year 1999=10/01/1998-9/30/1999). Historical weather data (e.g., precipitation and temperature) were obtained from the National Climatic Data Center website (NCDC). Thiessen polygon method (Hann et al., 1994) was used to calculate precipitation for the Panther Creek watershed.

Three weather stations (COOPID No. 411956, COOPIN No. 419067, and WBANID No. 53910) and their representative rainfall areas were identified using the Thiessen method. Data from 1999 to 2006 were collected from these three stations. River reach files of the Panther Creek watershed were downloaded from the USGS National Hydrography Dataset (NHD) website, and topographical data at 30-m resolution of this watershed were obtained from the USGS National Map Seamless Data Distribution System (USGS). The soil dataset used in this study was the 1:24,000 scale Soil Survey Geographic (SSURGO) database developed by the Natural Resources Conservation Service (NRCS).

Land use information for four years $(1984,1996,2001$, and 2005) was obtained from various national land use/land cover (LULC) datasets. The 1984 dataset was obtained from the U.S. Environmental Protection Agency (EPA) Geographic Information Retrieval and Analysis System (GIRAS) at $80-\mathrm{m}$ resolution (EPA Spatial Data Library). This dataset was then resampled to $30-\mathrm{m}$ resolution. The 1996 and 2005 datasets were obtained from the National Oceanic and Atmospheric Administration (NOAA) Coastal Services Center at 30-m resolution. The 2001 dataset was obtained from the USGS National Land Cover Dataset (NLCD; Homer et al., 2004) at 30-m resolution. Data accuracy of the 1996, 2001 and 2005 datasets ranges from 73\% to 85\% (Stehman et al., 2003; Homer et al., 2004; NOAA), and the 1984 dataset accuracy is at a lower level (EPA Spatial Data Library). Data accuracy of the above national datasets has been proved to be acceptable in various studies on land use patterns with respect to water quantity and quality assessment (Earls and Dixon, 2005; Wolter et al., 2006).

These national datasets are produced through classifying Landsat images into different LULC classes (Jensen, 2000). The urban land use class in the datasets comprises several densities based on the level of impervious cover. Low-density and medium-density urban developments have $20-49 \%$ and $50-79 \%$ impervious surfaces, respectively, and common land uses are single-family housing units. High-density urban development (80-100\% impervious surface) includes apartment complexes, row houses, and commercial/industrial/transportation facilities (Homer et al., 2004).

Yang et al. (2002) developed a method to quantify different levels of imperviousness in the urban land use class. For example, in developing the NLCD 2001 dataset, four imperviousness levels are determined via the following procedure. First, the impervious areas of several $1-\mathrm{m}$ resolution orthophoto quadrangles are estimated. Second, these impervious areas are cross referenced with the Land- 


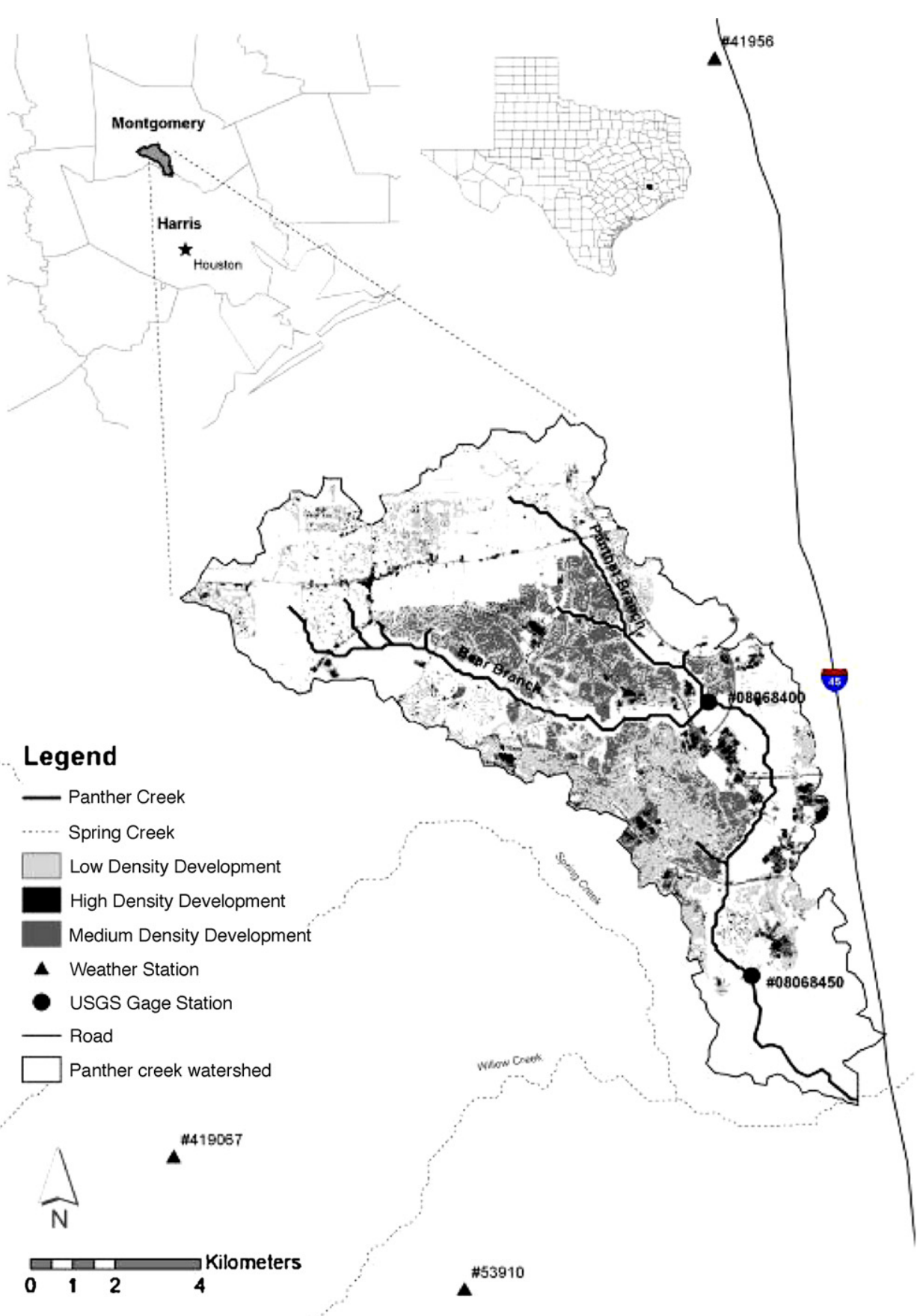

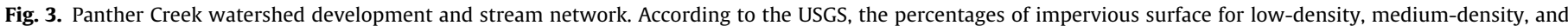
high-density development are $20-49 \%, 50-79 \%$, and $80-100 \%$, respectively.

sat scene to calibrate the relationship between percent impervious cover and the Landsat spectral data. Third, the above relationship is modeled using regression analysis. Last, the models are applied to all pixels in the Landsat scene to define the impervious cover level of each pixel. In this current study, the high and low impervious cover levels were referenced to create high- and low-density scenarios, respectively.

Eighteen LULC classes that were associated with The Woodlands development were used in this study. For simplicity, these classes were further grouped into seven categories: (1) water (open water, woody wetlands, and emergent herbaceous wetlands), (2) urban land uses (low-density residential, medium-density residential, high-density residential, and com- mercial/industrial/transportation), (3) forest (deciduous forest, evergreen forest, and mixed forest), (4) agriculture (pasture/hay, row crops, and small grains), (5) urban/recreational grasses, (6) grasslands/herbaceous and shrubland, and (7) others (bare rock/sand/clay and transitional).

\subsection{Measurement}

Two sets of analyses were conducted. In the first set of analyses, the above seven land use class categories were used to examine the LULC distribution in the Panther Creek watershed (The Woodlands) over the period of 1974-2005. In the second set of analyses, the original 18 LULC classes were reclassified to match the LULC classes 
Table 1

Impervious cover ratio index.

\begin{tabular}{|c|c|c|c|}
\hline Land use & Impervious percent range & Median & Ratio \\
\hline Residential low density & $20-49$ & 35 & 1.0 (baseline) \\
\hline Residential medium density & $50-79$ & 65 & 1.9 \\
\hline Residential high density & $80-100$ & 90 & 2.6 \\
\hline Commercial/industrial/transportation & $80-100$ & 90 & 2.6 \\
\hline
\end{tabular}

specified by the AGWA hydrological models.

\subsubsection{LULC distribution and development location}

The first set of analyses evaluated the extent to which The Woodlands development followed McHarg's ecological plan to preserve more lands with permeable soils than those with less permeable soils. The LULC distribution was examined in the watershed of four years (1984, 1996, 2001, and 2005). Furthermore, the grids were overlaid with soil grids to quantify the percentage of impermeable cover on each soil group. Soils in the watershed were grouped according to their hydrological properties defined by the U.S. Department of Agriculture (USDA, 2002). There are four hydrological soil groups: A, B, C, and D-A soils are sandy and loamy sand soils; B soils are sandy loam and loam soils; $C$ soils are silt loam and sandy clay loam soils; and D soils are clay loam, silty clay loam, and clay soils. A soils have the highest infiltration rate, $B$ and $C$ soils have moderate infiltration rates, and $\mathrm{D}$ soils have the lowest infiltration rate.

\subsubsection{Simulated land use scenarios}

The second set of analyses assessed the potential impact of different planning approaches on stream flow. Two important planning variables were examined in the scenarios. The first one was development density; the second development location, that is, which type of soil on which to place development.

2.3.2.1. Rationale for scenario. Scenario-based investigations of alternative futures contribute to informed planning and facilitate the decision-making process and they have been used in landscape and urban planning for over three decades. Scenarios serve two main functions: real-world planning for the future and scientific inquiry (modeling) (Xiang and Clarke, 2003).

Related to these two functions are the two main types of scenario-based studies: the "surprise-free" alternatives that explore reasonable and feasible futures and "novel" scenarios that investigate extreme conditions of benefits or risks (Shearer, 2005). Belonging to the second type, this study compared five extreme "what-if" land use scenarios that used different planning approaches and assessed the potential impact of these approaches on stream flow.
2.3.2.2. Considerations in creating scenarios. Three considerations were taken into account when creating scenarios. The first consideration was to maintain the total impervious cover area in the watershed. Impervious cover presents an important variable affecting watershed runoff. Generally, the higher the development density, the higher the impervious surface percentage and the more runoff that is generated (Schueler, 1994).

The Woodlands 2005 land use dataset was used to determine the percent of total impervious cover area in the watershed. An Impervious Cover Ratio Index (Table 1) was developed to capture the 2005 total impervious cover area and to create scenarios that maintained the same impervious cover area. To create Table 1 Index, the lowest median value (that of the low-density residential land) was assigned as the baseline value of 1 . Then, the index values of the medium-density residential land and highdensity residential land were calculated based on their median values of imperviousness. For instance, the impervious surface area of $2.6 \mathrm{Ha}$ of low-density residential land will approximate that of $1 \mathrm{Ha}$ of high-density residential land. The value of 2.6, as shown in Table 1 Index, was calculated by dividing 90 by 35 , where 90 is the median value of the impervious percent range of the high-density residential and 35 is that of the low-density residential.

The 2005 Panther Creek watershed (The Woodlands) percent of impervious cover area was calculated using Eq. (1). Variables in Eq. (1) are listed in Table 2. Since all the LULC datasets are at 30$\mathrm{m}$ resolution, the number of pixels was used as the surrogate for the land area. The calculated watershed percent of imperviousness (21.5\%) was kept constant when developing scenarios.

Imperviousness \%year 2005

$$
\begin{aligned}
& \text { No. } \text { low } \times 35 \%+\text { No.medium } \times 65 \%+\text { No.high }_{\text {. }} \times 90 \% \\
& + \text { No. }{ }_{\text {commercial/industrial/transportation }} \times 90 \% \\
& \text { No.watershed }
\end{aligned}
$$

Another closely related variable was the total developed area, primarily residential and commercial land uses. The 2005 watershed percent of total developed area was calculated using Eq. (2). Variables in Eq. (2) are also listed in Table 2. Note that the calculated 2005 watershed percent of total developed area (48.5\%) differed

Table 2

\begin{tabular}{|c|c|}
\hline Variable & Explanation \\
\hline Imperviousness (\%) & Percent of impervious cover of the Panther Creek watershed \\
\hline $\begin{array}{l}\text { No.low } \\
35 \%\end{array}$ & $\begin{array}{l}\text { Pixel number of low-density residential class } \\
\text { Median of impervious percent range (low-density residential) }\end{array}$ \\
\hline $\begin{array}{l}\text { No.medium } \\
65 \%\end{array}$ & $\begin{array}{l}\text { Pixel number of medium-density residential class } \\
\text { Median of impervious percent range (medium-density residential) }\end{array}$ \\
\hline $\begin{array}{l}\text { No.high } \\
90 \%\end{array}$ & $\begin{array}{l}\text { Pixel number of high-density residential class } \\
\text { Median of impervious percent range (high-density residential) }\end{array}$ \\
\hline $\begin{array}{l}\text { No. } \text { commercial/industrial/transportation } \\
90 \%\end{array}$ & $\begin{array}{l}\text { Pixel number of commercial/industrial/transportation class } \\
\text { Median of impervious percent range (commercial/industrial/transportation) }\end{array}$ \\
\hline No.watershed & Total pixel number of the Panther Creek watershed \\
\hline
\end{tabular}

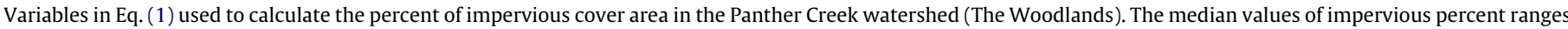
are presented in Table 1. 


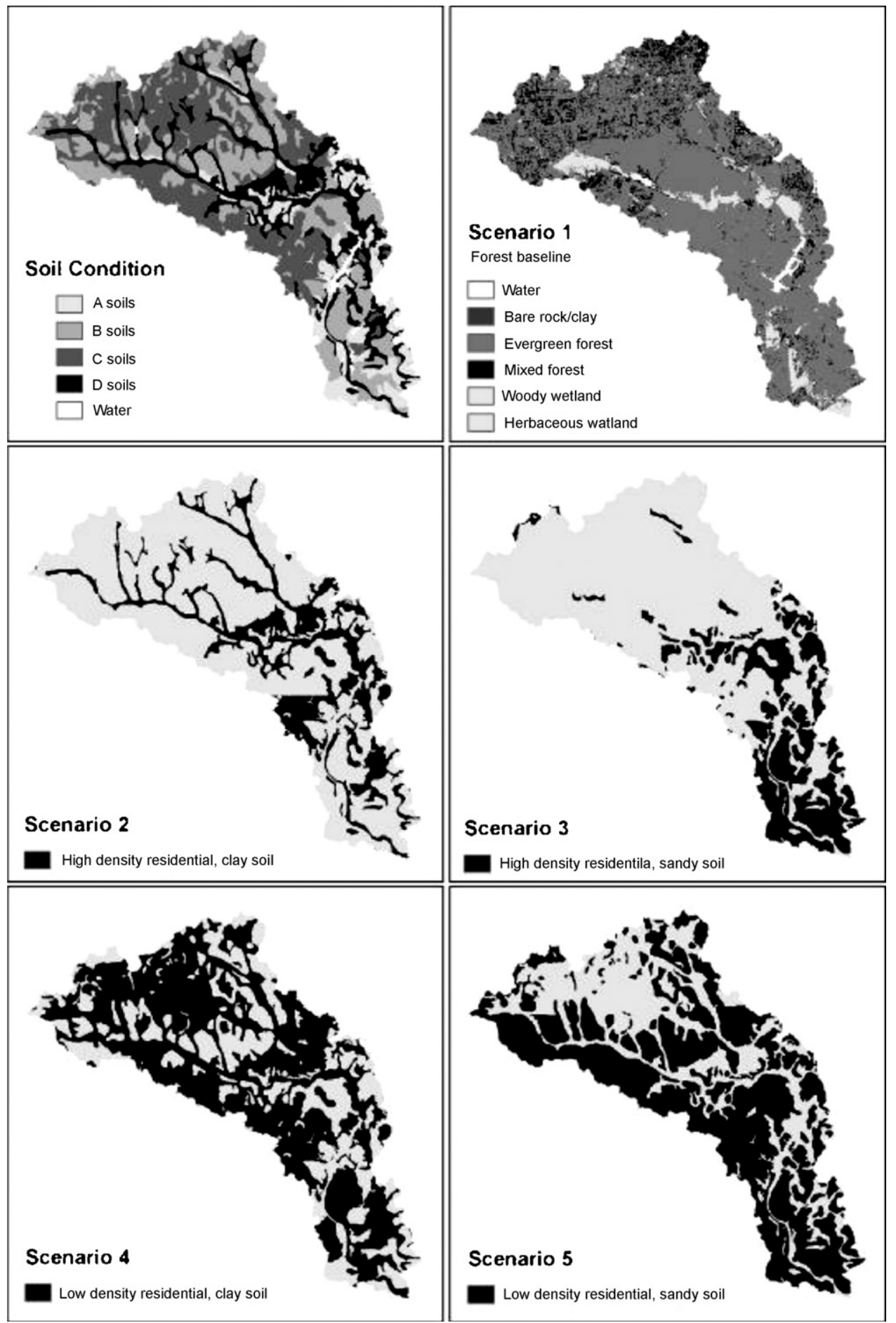

Fig. 4. Five hypothetical land use scenarios and watershed soil conditions.

from that of the scenarios, as explained in the following section.

Total developed area \%year 2005

$$
=\frac{\begin{array}{l}
\text { No.low }+ \text { No.medium }+ \text { No.high } \\
+ \text { No.commercial/industrial/transportation }
\end{array}}{\text { No.watershed }}
$$

The second consideration was to maintain the general trend of The Woodlands development in history. Historically, the first suburban village started downstream of Panther Creek, and devel- opment evolved along the creek to the north. Hence, in creating scenarios, the general trend of development from downstream to upstream was kept.

The third consideration was the location of development with respect to the location of soil type. This issue was addressed according to the purpose of each scenario. Fig. 4 shows five hypothetical scenarios that were in accordance with or were contrary to McHarg's planning approach of placing developments based on hydrological properties of soils. 
Table 3

Observed land use conditions and land use scenarios in the Panther Creek watershed (The Woodlands).

\begin{tabular}{|c|c|c|c|c|}
\hline Conditions and scenarios & Percent urban developed area & Percent impervious cover ${ }^{\mathrm{a}}$ & Watershed CN & Data $^{\mathrm{b}}$ \\
\hline 1984 Observed & 15 & 9.3 & 71.6 & EPA \\
\hline 1996 Observed & 37 & 15.9 & 72.1 & NOAA \\
\hline 2001 Observed & 47.9 & 20.9 & 77.6 & NLCD \\
\hline 2005 Observed & 48.5 & 21.5 & 80.4 & NOAA \\
\hline 1. Forest baseline & 0 & 0 & 66.9 & NOAA \\
\hline 2. High-density clay soil & 23.9 & 21.5 & 73.3 & NOAA \\
\hline 3. High-density sandy soil & 23.9 & 21.5 & 74.4 & NOAA \\
\hline 4. Low-density clay soil & 61.4 & 21.5 & 79.0 & NOAA \\
\hline 5. Low-density sandy soil & 61.4 & 21.5 & 80.8 & NOAA \\
\hline
\end{tabular}

a The median value of the impervious cover percentage range was used to calculate the percent impervious cover. The median values are presented in Table 1 . Scenarios 2-5 used the same amount of total impervious cover area as given for 2005.

b The land-use and land-cover datasets are 1984 EPA GIRAS data (80 m), 1996 and 2005 National Oceanic and Atmospheric Administration (NOAA) Coastal Services Center data (30 m), and 2001 USGS National Land Cover Dataset (NLCD) (30 m).

2.3.2.3. Scenarios. Five scenarios were created, including a forest baseline condition (Scenario 1), high-density scenarios (Scenarios 2 and 3), and low-density scenarios (Scenarios 4 and 5). High-density scenarios represent high-density residential land use plans and a large amount of open space is preserved from development in other parts of the watershed. Low-density scenarios employ the conventional Houston low-density development approach where low-density residence is promulgated in the watershed.

\section{(1) Baseline scenario}

- Scenario 1: forest baseline condition

- The Woodlands 2005 land use dataset was used to create this scenario. Urban developed areas (low-density residential, medium-density residential, high-density residential, and commercial/industrial/transportation) were reclassified into evergreen forest, and other nonurban land covers were maintained. Loblolly pine $(P$. taeda) evergreen forest was the site condition prior to development (Soil Conservation Service, 1972; McHarg, 1996). This scenario served as the baseline condition.

\section{(2) High-density scenarios}

To create high-density scenarios, medium-density and lowdensity residential and commercial/industrial/transportation land uses of 2005 were reclassified into high-density residential using ArcGIS. The watershed percent of total developed area in Scenarios 2 and 3 was calculated using Eq. (3). Variables in Eq. (3) are listed in Table 2. Scenarios 2 and 3 have the same total developed area and total impervious cover area. However, the development pattern varies as a result of the different purposes of the scenarios.

Total developed area \% $h$ high-density scenarios

$$
\begin{aligned}
& \text { No.low } \times(35 \% / 90 \%)+\text { No.medium }_{\text {. }} \times(65 \% / 90 \%)+\text { No.high } \\
& + \text { No.commercial/industrial/transportation } \\
& \text { No.watershed }
\end{aligned}
$$

- Scenario 2: high-density development on clay soil

- High-density residential development occurred on C and D soils. This scenario was the optimal condition in reducing surface runoff. It best adhered to McHarg's approach, which suggests placing development on soils with low infiltration capacities ( $C$ and $D$ soils) and preserving soils with high infiltration capacities (A and B soils).

- Scenario 3: high-density development on sandy soil

- High-density residential development occurred on A and B soils. Presumably, Scenario 3 would yield more runoff than Scenario 2, because Scenario 3 placed development on top of A and $B$ soils, instead of on C and D soils. Comparing Scenarios 2 and 3 would reveal the significance of development location per soil permeability in forecasting watershed runoff.

\section{(3) Low-density scenarios}

To create low-density scenarios, medium-density and highdensity residential and commercial/industrial/transportation land uses of 2005 were reclassified into low-density residential. The watershed percent of total developed area in Scenarios 4 and 5 was calculated using Eq. (4). Variables in Eq. (4) are also listed in Table 2. Likewise, Scenarios 4 and 5 have the same total developed area and total impervious cover area, whereas the development pattern varies as a result of the different purposes of the scenarios.

Total developed area\%low-density scenarios

$$
=\frac{\left.\begin{array}{l}
\text { No. }{ }_{\text {low }}+\text { No. }{ }_{\text {medium }} \times(65 \% / 35 \%)+(\text { No. } \\
+ \text { Nigh }
\end{array} \text { commercial/industrial/transportation }\right) \times(90 \% / 35 \%)}{\text { No.watershed }}
$$

Scenarios 4 and 5 represent conventional low-density residential development approaches ubiquitous in the United States. Compared with high-density scenarios, low-density scenarios have a larger total developed area and a smaller open space area, but the total impervious cover area stays the same.

- Scenario 4: low-density development on clay soil

- Low-density residential development first occurred on C and D soils. Lands with A and B soils were preserved as open space for stormwater detention and infiltration. It was expected that less runoff would be generated in Scenario 4 than in Scenario 5. Comparing Scenarios 4 and 5 should likewise reflect the importance of development location per soil permeability.

- Scenario 5: low-density development on sandy soil

- Low-density residential development first occurred on A and $B$ soils. Scenario 5 was the worst case scenario among the five in terms of runoff. This was because placing development on $\mathrm{A}$ and $\mathrm{B}$ soils would generate more runoff than development on C and D soils. Therefore, Scenario 5 would yield more runoff than Scenario 4. Further, low-density scenarios (Scenarios 4 and 5) would generate more runoff than high-density scenarios (Scenarios 2 and 3) as aforementioned.

The percentages of the total impervious cover area and the total developed area in the watershed of these scenarios are presented in Table 3. In this study, high-density scenarios are regarded as cluster compact development. This was because high-density development plans concentrate impermeable cover. Compared with low-density scenarios, high-density scenarios have lower percentages of total developed area in the watershed as a whole (see Eqs. (3) and (4) and Table 3). As a result, large amounts of open space 


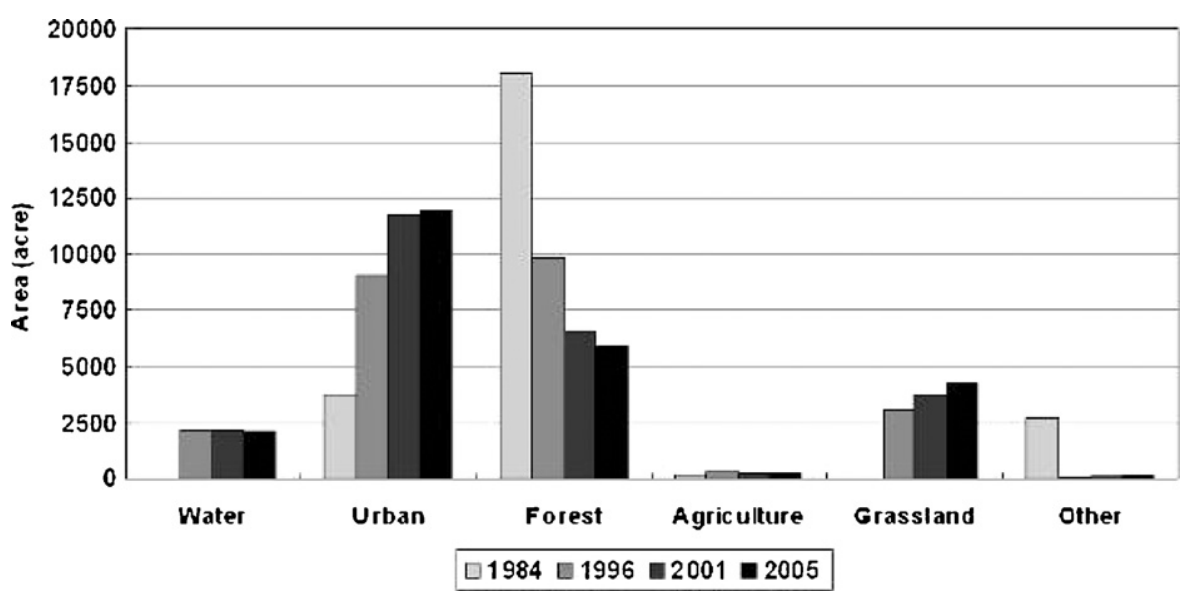

Fig. 5. Land use land cover distribution in the Panther Creek watershed (The Woodlands).

were preserved in high-density scenarios for stormwater detention and infiltration.

\subsubsection{Automated geospatial watershed assessment simulation}

In the second set of analyses, AGWA (Miller et al., 2007) was used to evaluate the hydrological consequences of urban development in the watershed. AGWA is a multipurpose hydrological tool for watershed modeling. Embedded in ArcGIS interfaces, AGWA combines two extensively used watershed hydrological models: the Soil and Water Assessment Tool (SWAT) (Arnold et al., 1994) and the Kinematic Runoff and Erosion model (KINEROS) (Smith et al., 1995). SWAT is a hydrological and water quality model for long-term watershed simulations. Although it is widely used in agriculture dominated land uses (Srinivasan and Arnold, 1994), SWAT could also be used for urban watershed modeling (Arnold and Fohrer, 2005). KINEROS is an event-driven model designed to simulate runoff and erosion for single-storm events in small watersheds. In KINEROS, a network of channels and planes is used to represent a watershed and the flood routing is based on the kinematic wave method (Smith et al., 1995).

The main reason of using SWAT was because the concept of SWAT is in accordance with McHarg's planning approach. In SWAT, each unique combination of land use and soil type generates a Hydrological Response Unit (HRU). Superimposing various land use types onto different soil patches allows runoff estimates for comparison. Each HRU is directly related to a Curve Number (CN) (Srinivasan and Arnold, 1994), and CN is determined by land use and soil type (Hann et al., 1994). Therefore, McHarg's approach of allocating land use based on soil type could be assessed with SWAT.

For the purpose of this study, CN was the main parameter calibrated in the SWAT model to reflect the 2005 LULC condition. In the KINEROS model, Manning's roughness coefficient (Manning's $n$ ) and $\mathrm{CN}$ were the parameters calibrated. In SWAT, the average runoff depths of the watershed from 2001 to 2005 were simulated. In KINEROS, the Soil Conservation Service's rainfall frequency maps (Soil Conservation Service, 1986) were used to generate 24-h storm events of four return-periods (10, 25, 50, and 100 years). In each scenario, the composite $\mathrm{CN}$ of the watershed was calculated using Eq. (5):

$\mathrm{CN}_{\text {composite }}=\frac{\sum_{i} A_{i} \mathrm{CN}_{i}}{\sum_{i} A_{i}}$

where $A_{i}$ is the area of sub-watershed $i$ and $\mathrm{CN}_{i}$ is the $\mathrm{CN}$ of subwatershed $i$.
The SWAT model simulation was run for a five-year period (2001-2005) following a two-year warm-up period (1999-2000). The warm-up period was used to establish appropriate initial conditions for soil water storage. Then the five-year period was divided into two parts to perform model calibration (2001-2003) and validation (2004-2005). USGS measured data were used for calibration. In the calibration process, a base flow program was used to screen the base flow component in the USGS measured flows in order to increase SWAT model efficiency (Arnold and Allen, 1999). The SWAT model efficiency was assessed by two criteria. The first criterion is the Nash and Sutcliffe coefficient (Nash and Sutcliffe, 1970), calculated with Eq. (6):

$E=1-\frac{\sum\left(Q_{\mathrm{obs}}-Q_{\mathrm{sim}}\right)^{2}}{\sum\left(Q_{\mathrm{obs}}-Q_{\text {mean }}\right)^{2}}$

where $E$ is the coefficient of efficiency; $Q_{\text {obs }}$ is the observed stream flow (mm); $Q_{\text {sim }}$ is the simulated stream flow (mm); and $Q_{\text {mean }}$ is the mean observed stream flow during the evaluation period. $E$ varies from minus infinity to 1 , with 1 representing a perfect fit of the model. The second criterion is regression analysis. For calibration, regression analysis shows how well the simulated data match the measured data. For validation, regression analysis shows how accurately the calibrated model predicts the subsequent measurements.

\section{Results}

\subsection{LULC distribution and development location}

The Woodlands (Panther Creek watershed) has experienced fast-paced residential and commercial developments in the past three decades. Especially after the 1997 ownership change, the final date of completion is expected to be 10 years earlier than the date anticipated by the original developer, George Mitchell (Galatas and Barlow, 2004). By 2005, around half of the watershed was composed of urban land uses (Fig. 5).

As previously mentioned, McHarg's planning approach had experienced several changes, and notable adjustments were made in 1985 and 1997 (Girling and Helphand, 1994; Galatas and Barlow, 2004). Coincidentally, national LULC datasets of 1984 and 1996 could reflect the development conditions before these changes, and development was accordingly divided into three periods: 1972-1984, 1985-1996, and 1997-2005. In addition, each period is associated with a development zone where the majority of the development occurred during that period. 


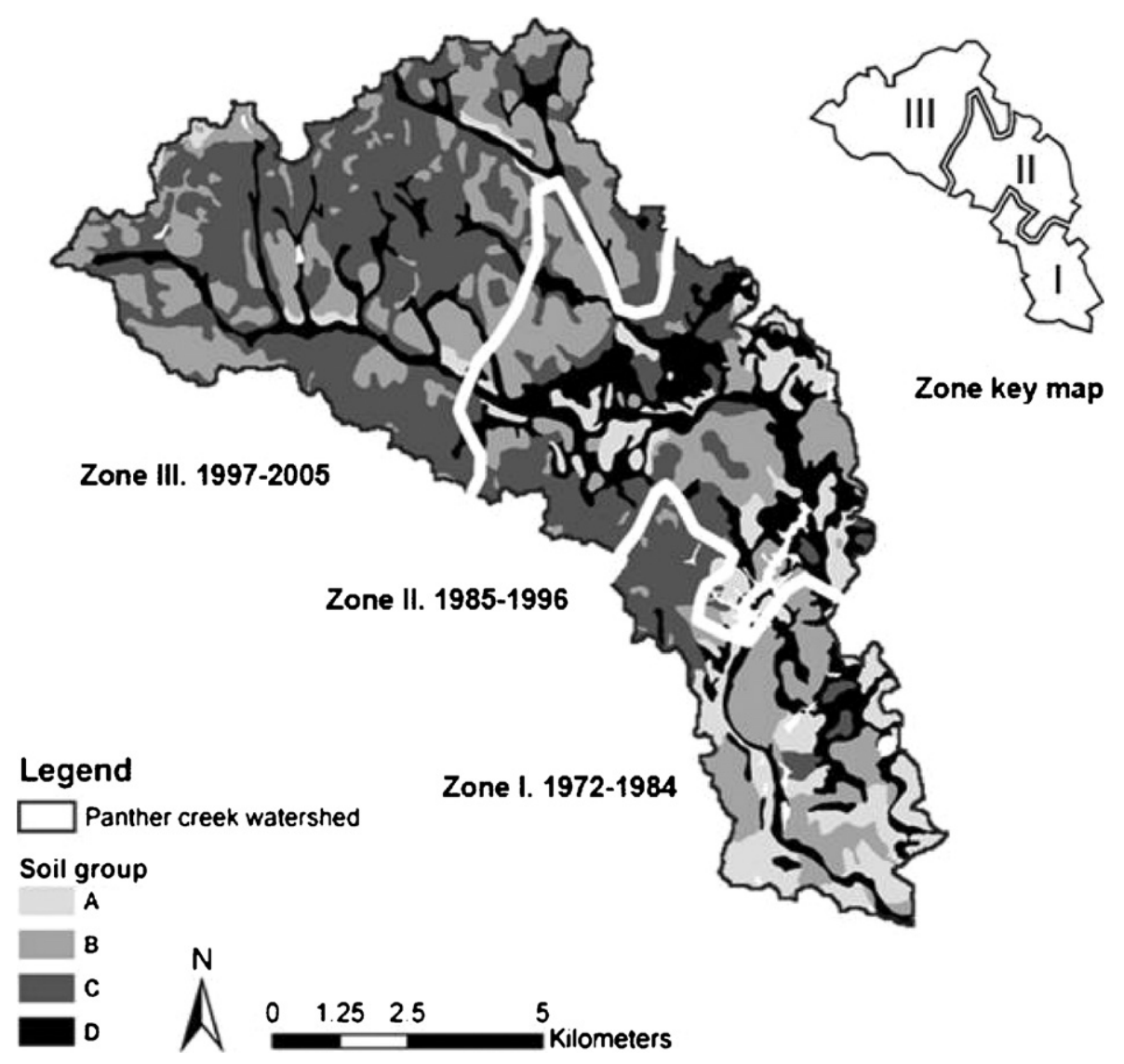

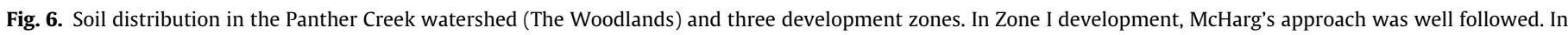
Zone II and Zone III development, McHarg's approach was largely abandoned.

Fig. 6 presents the three zones and periods and the distribution of hydrological soil groups in the Panther Creek watershed. Fig. 7 shows the developed area of each zone for different soil groups and periods. Developed areas consist of various urban land uses, including low-density residential, medium-density residential, high-density residential, and com-

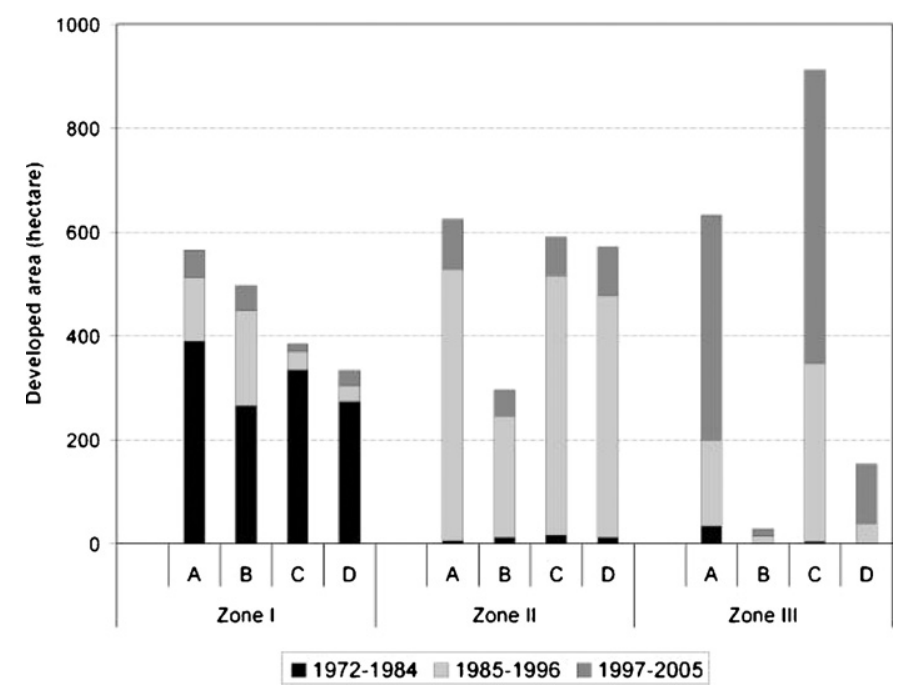

Fig. 7. Development area on different hydrological soil groups in three development zones during three time periods in the Panther Creek watershed (The Woodlands). Numbers indicate additional development in stead of accumulative development areas. In Zone I, majority of the development occurred during 1972-1984, in Zone II during 1985-1996, and in Zone III during 1997-2005. mercial/industrial/transportation. As Fig. 7 shows, development occurred mainly during 1972-1984 in Zone I, during 1985-1996 in Zone II, and during 1997-2005 in Zone III. Also notice that infill developments occurred in Zone II and Zone III in the two later periods.

Table 4 and Table 5 further combine the data from Fig. 7 to create a dichotomy of soil groups: the A and B soil group indicates soils with sound infiltration capacities, and the $C$ and $D$ soil group represents soils with poor infiltration capacities. Table 4 shows the land areas of each soil group, and Table 5 lists development areas placed on each soil group in each time period.

In Zone I, the land area of A and B soils ( $1327 \mathrm{Ha}$ ) is $63 \%$ more than that of $C$ and D soils ( $813 \mathrm{Ha}$ ). Generally speaking, it is challenging to follow the natural soil pattern to overlay urban infrastructure and various developments. For example, layout of a road network needs to consider engineering principles, safety and sometimes aesthetic views. Complete match between a proposed road network and the random soil pattern is nearly impossible. Although it is true that more development occurred on A and B soils than on C and D soils, the percentage of developed area on A and B soils (49\%) was less

Table 4

Land area and area percentage of two soil groups (A and B; C and D) in three development zones in the Panther Creek watershed (The Woodlands). The A and B soil group represents soils with good infiltration capacities, and the C and D soil group represents soils with poor infiltration capacities.

\begin{tabular}{|c|c|c|c|c|c|}
\hline & \multirow[t]{2}{*}{ Zone area (ha) } & \multicolumn{2}{|c|}{$A$ and $B$} & \multicolumn{2}{|c|}{ C and D } \\
\hline & & ha & $\%$ & ha & $\%$ \\
\hline Zone I & 2140 & 1327 & 62 & 813 & 38 \\
\hline Zone II & 3232 & 1351 & 42 & 1881 & 58 \\
\hline Zone III & 4567 & 1611 & 35 & 2956 & 65 \\
\hline
\end{tabular}


Table 5

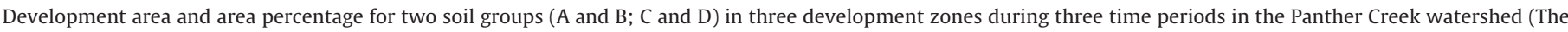
Woodlands). Numbers indicate additional rather than accumulative development areas in each period.

\begin{tabular}{|c|c|c|c|c|c|c|}
\hline & \multirow[t]{2}{*}{ A and $B(h a)$} & \multicolumn{2}{|c|}{ Development on A and B } & \multirow[t]{2}{*}{ C and D (ha) } & \multicolumn{2}{|c|}{ Development on C and D } \\
\hline & & ha & $\%$ & & ha & $\%$ \\
\hline \multicolumn{7}{|c|}{$1972-1984$} \\
\hline Zone I & 1327 & 654 & 49 & 813 & 606 & 75 \\
\hline Zone II & 1351 & 17 & 1 & 1881 & 27 & 1 \\
\hline Zone III & 1611 & 33 & 2 & 2956 & 3 & 0 \\
\hline \multicolumn{7}{|c|}{ 1985-1996 } \\
\hline Zone I & 1327 & 306 & 23 & 813 & 67 & 8 \\
\hline Zone II & 1351 & 757 & 56 & 1881 & 964 & 51 \\
\hline Zone III & 1611 & 180 & 11 & 2956 & 382 & 13 \\
\hline \multicolumn{7}{|c|}{ 1997-2005 } \\
\hline Zone I & 1327 & 100 & 8 & 813 & 44 & 5 \\
\hline Zone II & 1351 & 146 & 11 & 1881 & 168 & 9 \\
\hline Zone III & 1611 & 447 & 28 & 2956 & 678 & 23 \\
\hline
\end{tabular}

than that on C and D soils (75\%). This result suggests that A and B soils were given priority of preservation in Zone I development and McHarg's approach was followed during 1972-1984.

In Zone II during 1985-1996, A and B soils ceased to be the priority of preservation. The land area of A and B soils $(1351 \mathrm{Ha})$ is smaller than that of $C$ and D soils (1881 Ha) in Zone II. Yet, a higher percentage of A and B soils was developed (56\%) than that of $C$ and D soils (51\%). In the meantime, $306 \mathrm{Ha}$ of infill development were placed on A and B soils in Zone I, which accounted for $23 \%$ of Zone I area. In contrast, the other part of the infill development in this zone was 67 hectares of development on C and D soils, only $8 \%$ of the zone's area. This result is consistent with the literature that suggests McHarg's approach was less well followed after 1985 (Girling and Helphand, 1994).

In Zone III during 1997-2005, the departure from McHarg's approach was further demonstrated. Even though the land area of A and B soils $(1611 \mathrm{Ha})$ is only $55 \%$ of that of $C$ and D soils $(2956 \mathrm{Ha})$ in this zone, a higher percentage of A and B soils (28\%) than C and D soils (23\%) was developed. Similar developments that ignored soil permeability also occurred in Zones I and II during the 1997-2005 period. Evidently, developments post 1997 had largely abandoned McHarg's planning approach.

\subsection{SWAT simulation}

\subsubsection{CN modeling}

Developed by NRCS (Hann et al., 1994), CN indicates the site infiltration and runoff relationship, with a range between 0 and 100 . The higher the $\mathrm{CN}$, the larger the runoff volume generated. $\mathrm{CN}$ of 100 indicates no infiltration capacity. SWAT model calculated the watershed CNs for the five scenarios and the actual conditions of four different years. The $\mathrm{CN}$ results are presented in Table 3. Anthropogenic land uses (e.g., residential and commercial) were grouped together as urban developed area. The simulation yielded expected results, in which the high-density scenarios (Scenarios 2 and 3) had lower CNs than the low-density scenarios (Scenarios 4 and 5). This was mainly because the high-density scenarios have smaller total developed areas than the low-density scenarios.

It was also found that The Woodlands actual development condition in 2005 was similar to the worst case scenario (Scenario 5 , low-density development on sandy soils) simulated in the watershed modeling. CNs of the 2005 actual condition and the worst case scenario (Scenario 5) were 80.4 and 80.8, respectively. This indicates that watershed runoff volume of 2005 was similar to that of the Houston conventional low-density development. This result was not expected and details are discussed in Section 4.

\subsubsection{Calibration and validation}

Calibration and validation were performed on SWAT and KINEROS models. In SWAT, CN was adjusted, while in KINEROS CN and Manning's $n$ were adjusted. Simulated flows were compared with USGS measured flows. The calibrated models were then used for simulation of five scenarios. SWAT calibration shows promising results in The Woodlands watershed modeling. As shown in Fig. 8, USGS measured flows can be reasonably predicted by the SWAT model after calibration. The Nash and Sutcliffe (N-S) model efficiencies also confirm the calibration and validation results (Table 6). According to Van Liew and Garbrecht (2003), simulation with yearly data is considered "good" when the N-S efficiencies are greater than 0.75 . When using monthly data, values of $\mathrm{N}-\mathrm{S}$ efficiencies greater than 0.52 are considered as good results.

\subsubsection{Stormwater runoff}

Using the observed weather data (2001-2005), the SWAT model simulated the annual surface runoff for the five land use scenarios, and the results are presented in Fig. 9. As expected, the high-density scenarios generated lower amounts of runoff than the low-density scenarios. For the low-density sandy soil scenario (Scenario 5), where $A$ and $B$ soils were used for development and became impervious covers, the value was the highest. All land use scenarios produced higher runoff compared with the forest condition (Scenario 1). On average, high-density scenarios generated around $40-50 \%$ more runoff than the forest condition, and low-density scenarios increased these values to around $90-100 \%$. Also note that the differences between the two soil groups were not as pronounced as the differences between the two density groups.

Table 7 shows the average values (2001-2005) of the watershed outputs. The trend was evident that surface runoff increased as development density decreased, where situations became worse when A and B soils were paved over. Likewise, a similar trend was predicted that less aquifer recharge and more sediment loading were expected when low-density development spread in the watershed. From the forest baseline scenario (Scenario 1) to the low-density development scenarios (Scenarios 4 and 5), sediment loading and surface runoff almost doubled, whereas aquifer recharge reduced to less than $50 \%$ of the forest condition.

Similar to the results in Fig. 9, Table 7 shows that the differences of watershed outputs between the two density groups were larger than the differences between the two soil groups. For example, the low-density sandy soil scenario (Scenario 5) would generate 3.4 million $\mathrm{m}^{3}$ more runoff than the low-density clay soil scenario (Scenario 4 ) on a yearly basis (8\% increase). However, in comparing the low-density sandy soil scenario (Scenario 5) with the high-density sandy soil scenario (Scenario 3), a more significant increase of 12.3 million $\mathrm{m}^{3}$ runoff ( $34 \%$ increase) would occur. 


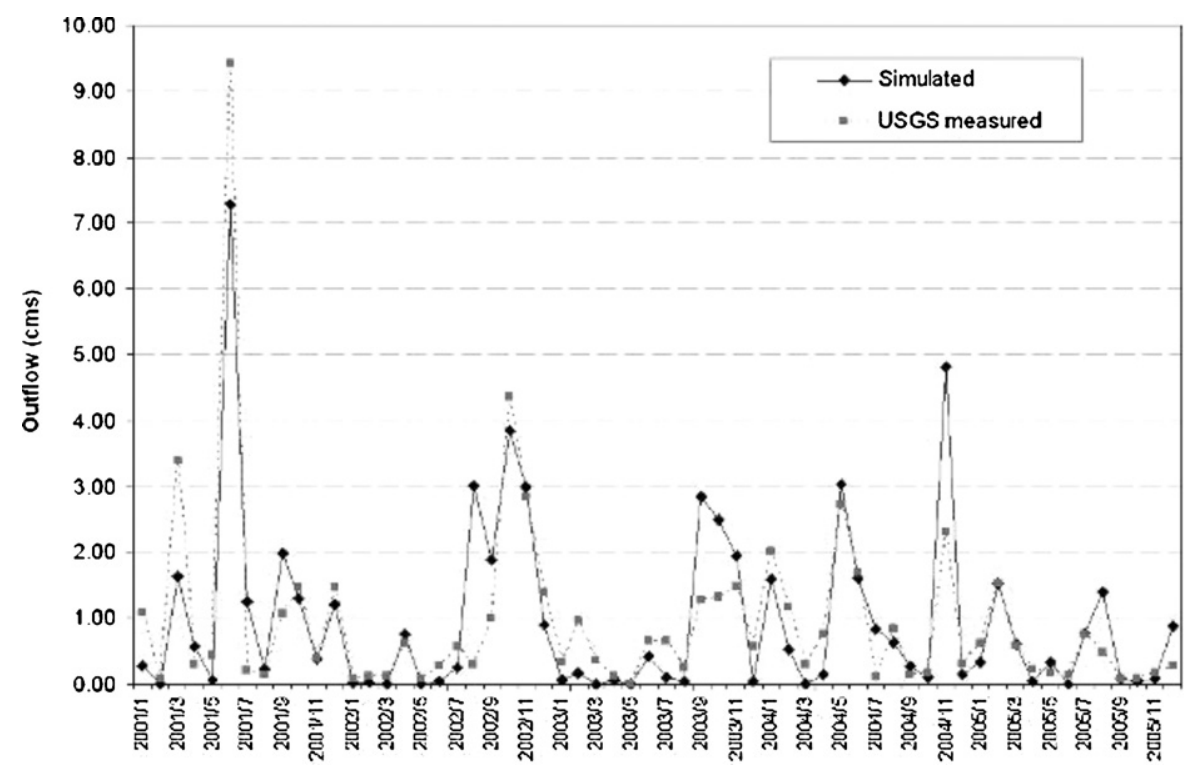

Fig. 8. Simulated and observed surface runoff by SWAT for the calibration and validation periods at USGS gauge station \#08068450.

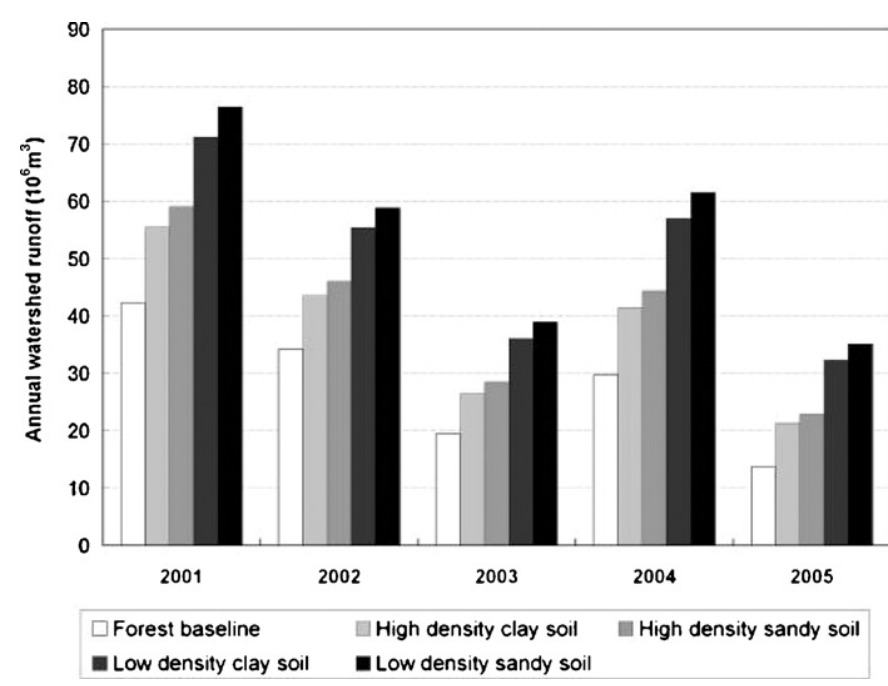

Fig. 9. Simulated annual surface runoff of five land-use scenarios.

\subsection{KINEROS simulation}

\subsubsection{Peak flow}

Rainfall return frequencies of $10,25,50$, and 100 years were simulated and are presented in Fig. 10. As expected, the highdensity scenarios-high-density clay soil scenario (Scenario 2) and high-density sandy soil scenario (Scenario 3)-generated lower peak discharge than the low-density scenarios-low-density clay soil scenario (Scenario 4) and low-density sandy soil scenario (Scenario 5)-for all four frequencies. In addition, the differences between the two density scenarios were not substantial during small rainfall frequencies (i.e., 10 years [not shown] and 25 years). But the differences became more prominent as the rainfall frequency decreased (i.e., 50 and 100 years). The low-density clay soil scenario (Scenario 4) and the low-density sandy soil scenario (Scenario 5) could create a peak discharge around nine times of what the high-density clay soil scenario (Scenario 2) and the high-density sandy soil scenario (Scenario 3) could have during a 100-year storm.

Similar to the SWAT results, the differences between the two soil groups were less compared with the differences between two density groups. The variations within each density group decreased as the storm frequencies decreased. However, the differences in peak

Table 6

Model efficiency and statistics from ordinary least squares regression analyses for the calibration and validation periods.

\begin{tabular}{|c|c|c|c|c|c|c|}
\hline \multirow[t]{3}{*}{ USGS gauge } & \multicolumn{4}{|c|}{ Nash-Sutcliffe coefficient } & \multicolumn{2}{|l|}{$R^{2}$} \\
\hline & \multicolumn{2}{|l|}{ Calibration } & \multicolumn{2}{|l|}{ Validation } & \multirow{2}{*}{$\begin{array}{l}\text { Calibration } \\
\text { (monthly) }\end{array}$} & \multirow{2}{*}{$\begin{array}{l}\text { Validation } \\
\text { (monthly) }\end{array}$} \\
\hline & (monthly) & (yearly) & (monthly) & (yearly) & & \\
\hline \#8068450 & 0.76 & 0.97 & 0.63 & 0.92 & 0.76 & 0.70 \\
\hline \#8068400 & 0.71 & 0.79 & 0.59 & 0.98 & 0.72 & 0.58 \\
\hline
\end{tabular}

Note: Linear regression analysis, $y=a+b x$; independent variable $x$ is precipitation $(\mathrm{mm})$, dependant variable $y$ is stream flow $\left(\mathrm{m}^{3} \mathrm{~s}^{-1}\right)$.

Table 7

Simulated watershed outputs, average of years 2001-2005.

\begin{tabular}{|c|c|c|c|}
\hline Scenario & Surface runoff $\left(10^{6} \mathrm{~m}^{3}\right)$ & Total aquifer recharge $\left(10^{6} \mathrm{~m}^{3}\right)$ & Total sediment loading (tons/year) \\
\hline 1. Forest baseline & 25.1 & 36.0 & 565.0 \\
\hline 2. High-density clay soil & 33.8 & 27.9 & 753.3 \\
\hline 3. High-density sandy soil & 36.1 & 25.9 & 753.3 \\
\hline 4. Low-density clay soil & 45.0 & 18.2 & 1035.8 \\
\hline 5. Low-density sandy soil & 48.4 & 14.9 & 1035.8 \\
\hline
\end{tabular}




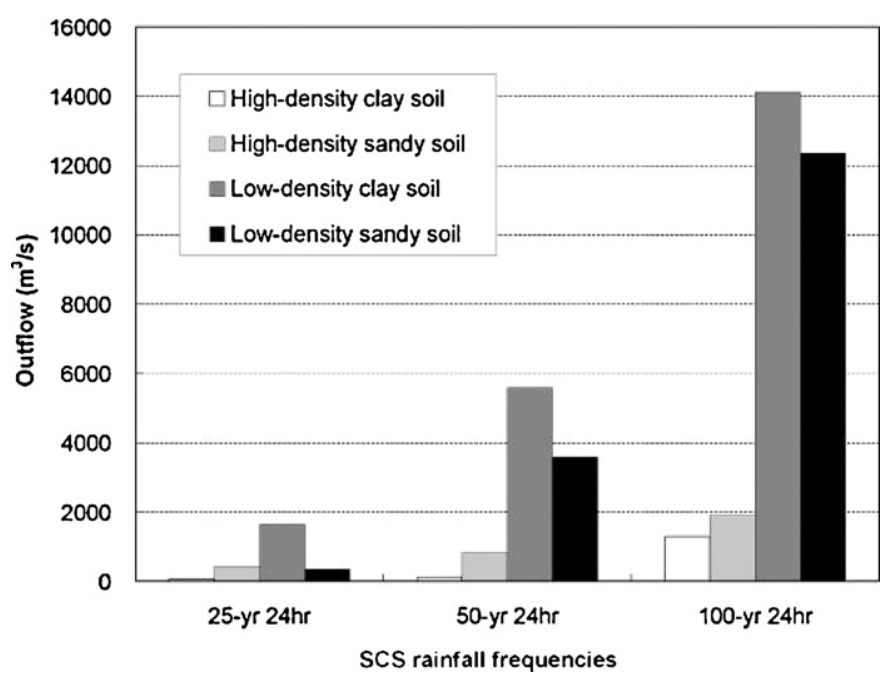

Fig. 10. Simulated watershed peak discharges of four land use scenarios during three rainfall frequencies.

discharges between the high-density scenarios were large. During a 100-year storm, the high-density sandy soil scenario (Scenario 3) generated around 50\% more peak discharge than the high-density clay soil scenario (Scenario 2). During smaller storms (25 and 50 years), the high-density sandy soil scenario (Scenario 2) generated around six times more peak discharge than the high-density clay soil scenario (Scenario 3). Finally, it was unexpected that the low-density sandy soil scenario (Scenario 5), where A and B soils were paved over, generated less peak discharge than the low-density clay soil scenario (Scenario 4), which preserved A and B soils for stormwater infiltration.

\subsubsection{Peak discharge spatial distribution}

The spatial patterns of peak discharge at a 100-year frequency are presented in Fig. 11. Peak discharges were higher in urbanized sub-watersheds than in sub-watersheds that remained natural conditions. In addition, peak discharges increased as the percentages of development increased. Peak discharge patterns in Fig. 11 resembled the land use distributions in Fig. 4. Similar peak discharge patterns were found in other storm frequencies $(10,25$, and 50 years), but the variations between sub-watersheds became less exaggerated as storm frequencies increased.

\section{Discussion}

These results indicate that The Woodlands land use conditions were worse than what the original McHarg plan proposed. The 2005 $\mathrm{CN}$ (80.4) is close to that of the low-density residential sandy soil scenario (80.8), the worst case scenario in this study. This value is also as high as that of the conventional quarter-acre single family residential land use (USDA, 2002), and this condition does not approximate the LID recommendations. Unfortunately, in Zone II and Zone III developments, soils with good infiltration capacities were not given the first priority in the community plan. After The Woodlands ownership changed in 1997, McHarg's approach was largely abandoned.

Development density plays an important role in affecting $\mathrm{CN}$ and watershed runoff. Watershed runoff increases around 35\% for high-density scenarios and around $85 \%$ for low-density scenarios compared with the forest baseline condition. Likewise, sediment yields increase around 30\% and $80 \%$ for high- and lowdensity scenarios, respectively. These results are also consistent with previous studies on the relationship between development densities and watershed outputs (Hammer, 1972; Schueler, 1994).
Schueler (1994) reported that compact development could reduce site imperviousness by $10-50 \%$ and yield less sediment than a dispersed impervious surface. This study further demonstrates that even when the total imperviousness is held constant, high-density compact development generates $40 \%$ less runoff than low-density development. Compared with "typical development" in Houston, which often increases peak flows by $180 \%$, flow in The Woodlands would increase by only 55\% according to a simulation study conducted in the 1970s (Spirn, 1984). This finding is consistent with the findings of this study that predicts the increase in runoff of around $50 \%$ for high-density development and $100 \%$ for low-density development, if McHarg's approach is followed.

Besides density, the other focus of this study was development location, that is, the ideal place to allocate development by soil type. SWAT model shows that the long-term watershed outflows differs slightly (7-8\%) between the two options in each density group. In other words, development on clay or sandy soils does not yield much difference in the long-term watershed outflow. However, the differences become extraordinary in extreme storms as shown by the KINEROS model. In a 100-year storm, the high-density sandy soil scenario (Scenario 3) could generate around 50\% higher peak discharge than the high-density clay soil scenario (Scenario 2).

In short, for long-term watershed runoff and during small rainfall events, development density is a more prominent factor than development location. The development location per soil permeability becomes important when extreme rainfalls (e.g., 50 and 100 years) are of concern. Developments that preserve highly permeable soils are less prone to flooding. The high-density clay soil scenario (Scenario 2) represents the best solution among the four development scenarios. The low-density scenarios (Scenarios 4 and 5)-conventional development typically found in the Houston area-are the least effective plans in stormwater management. Therefore, a more comprehensive development approach is to consider both density and location.

Another finding that corresponds to previous studies is that the pattern of development in the watershed has an influence on peak discharge (Bedient et al., 1985). In the Panther Creek watershed, there are more A and B soils than $C$ and $D$ soils in the lower reaches. The research design thus led more development to be placed on the lower portion of the watershed in the high-density sandy soil scenario (Scenario 3 ) and the low-density sandy soil scenario (Scenario 5 ) than in the high-density clay soil scenario (Scenario 2) and the low-density clay soil scenario (Scenario 4). Hence, different development locations caused differences in peak discharges among sub-watersheds. The low-density sandy soil scenario (Scenario 5), although it was projected to be the worst case scenario, generated less peak discharges than the low-density clay soil scenario (Scenario 4). This result could be attributed to the large open space preserved in the upper reaches of the watershed in the low-density sandy soil scenario (Scenario 5) that detained a large amount of runoff and retarded the momentum of peak discharge when it flowed to the watershed outlet. There are vast differences between each subwatershed in terms of development densities and soil conditions across the four scenarios. For this reason, comparing peak discharge of each sub-watershed in different scenarios was not possible in this study.

Today, development pattern in The Woodlands presents a gradient from adherence to abandonment of McHarg's approach. In the early period, the pattern was largely determined by an important environmental factor-soil permeability. In the later period, especially after 1997, the pattern gradually shifted to conventional "cookie-cutter" Houston type of development. Soil permeability, as defined by NRCS hydrological soil group, has been a good consideration in the selection of building locations. The common practice is to place building foundations on sandy soils and to avoid clay soils, because sandy soils provide better drainage and have a higher bear- 

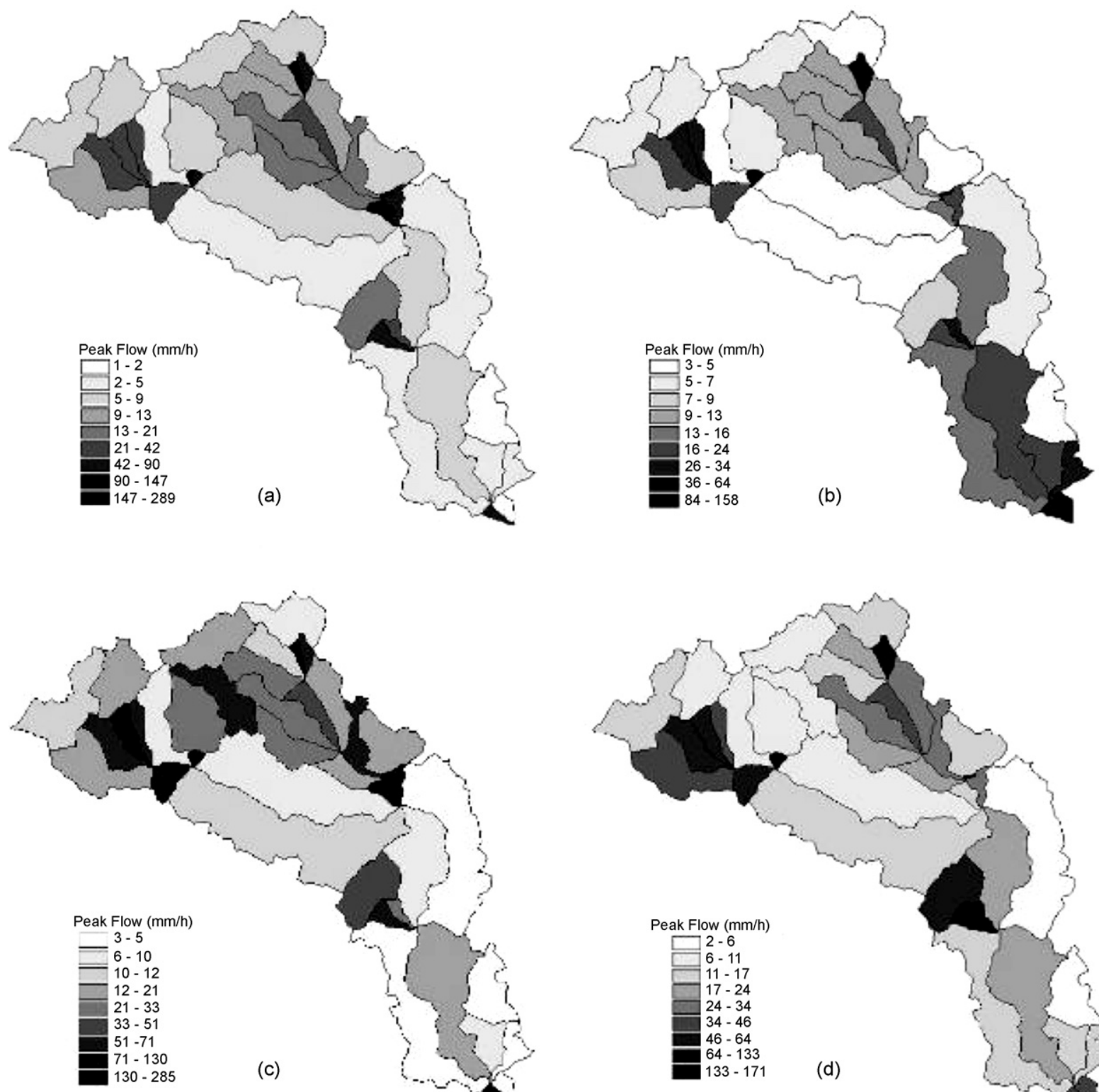

(c)

(c)
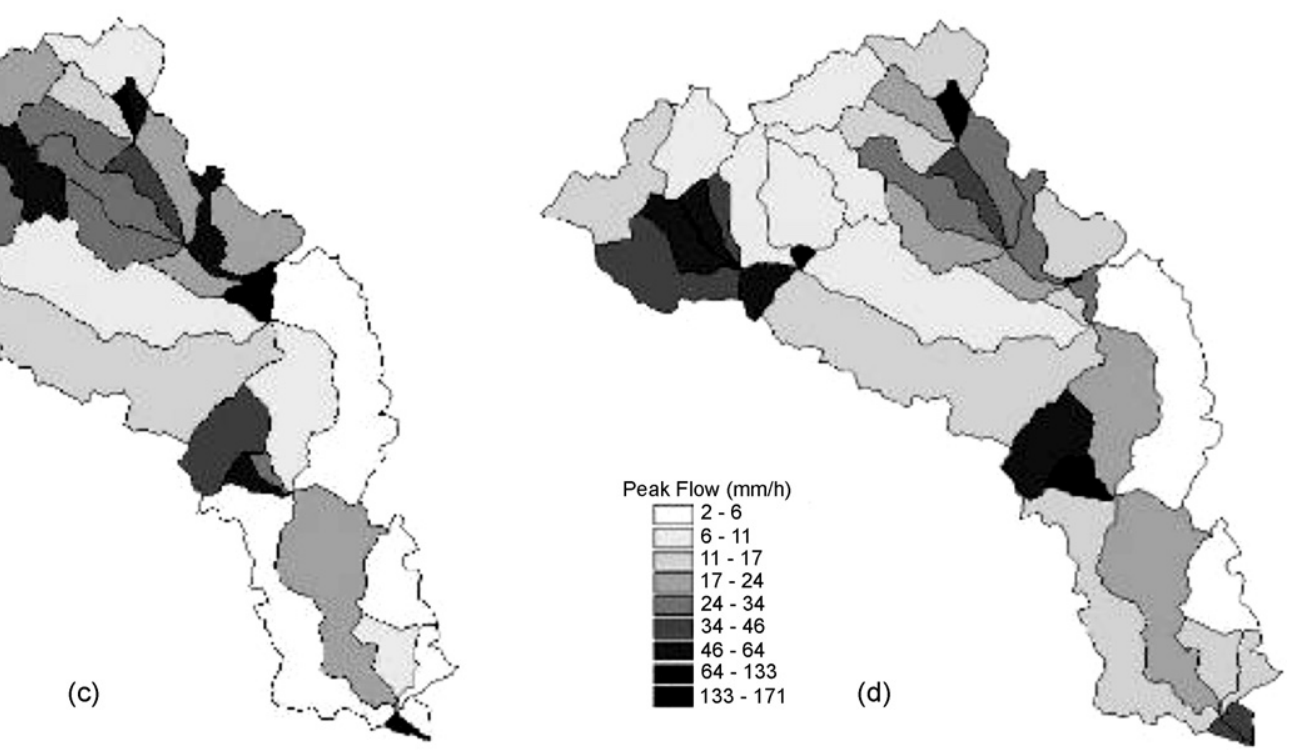

Fig. 11. Spatial distribution of peak discharge during 100-year storms. (a) High-density clay soil scenario (Scenario 2), (b) high-density sandy soil scenario (Scenario 3), (c) low-density clay soil scenario (Scenario 4), and (d) low-density sandy soil scenario (Scenario 5).

ing capacity than clay soils. To build foundations on clay soils may require special treatment, which adds to the construction cost.

McHarg's concept is in contrast to the common practice and expands from site-level scale to community and regional scales. In The Woodlands development, McHarg suggested building on clay soils while preserving sand soils, to respond to a major site constraint-flooding hazard in the Houston coastal area (McHarg, 1996). As indicated by historical extreme storms, this concept used in the first two suburban villages evidently minimized the potential flooding damage to the community property (Girling and Kellett, 2005). The additional cost due to the special treatment of building foundations thus became minor.

\section{Conclusions}

When integrating urban development into the natural system, planners and landscape architects must seek harmony rather than produce conflict. There are several important factors affecting stormwater runoff, including precipitation volume and intensity, time parameters, and soil permeability. Perhaps the only factor that designers can manipulate is ground cover (density, configuration, and surface texture). McHarg's plan for The Woodlands was based on a profoundly simple concept: coordinating development density and land use based on the hydrological properties of the soils. His plan aimed to maintain the natural hydrological conditions and to minimize urbanization impacts.

The Woodland's 2005 land use condition has deviated from McHarg's original plan. In particular, developments post 1997, the year of The Woodlands' ownership change, did not use soil permeability as a critical guide for planning. Watershed stream flow modeling on different hypothetical scenarios strongly suggests that compact high-density development combined with McHarg's approach is the best solution among development approaches compared in this study. Using soil permeability to coordinate development densities and land use presents a viable solution to the flooding problems in community development.

Finally, it is important to reiterate that this study only examined snapshots of development conditions of four years. Future 
study needs to include more samples that present more variations of the watershed conditions. The Woodlands' current conditions, despite having a quality that is less than originally proposed, are further ahead than conventional solutions. The Woodlands' planning, design, and management present an excellent example of eco-conscious urban planning for design professionals to consider.

\section{Acknowledgements}

This study is funded by the Texas Water Resource Institute (TWRI) through the USGS 104B program (Project No. 06HQGR0130). We thank anonymous reviewers for valuable comments which significantly improve this manuscript. We also greatly appreciate Dr. Chang-Shan Huang, Dr. Jon Rodiek, Dr. George Rogers and Dr. Ben Wu for helpful discussions and great support of this study.

\section{References}

Alberti, M., Booth, D., Hill, K., Coburn, B., Avolio, C., Coe, S., et al., 2007. The impact of urban patterns on aquatic ecosystems: an empirical analysis in Puget lowland sub-basins. Landscape Urban Plan 80 (4), 345-361.

Alberti, M., Marzluff, J.M., 2004. Ecological resilience in urban ecosystems: linking urban patterns to human and ecological functions. Urban Ecosystems 7 (3), 241-265.

Arnold, C.L., Gibbons, C.J., 1996. Impervious surface coverage-the emergence of a key environmental indicator. J. Am. Plann. Assoc. 62 (2), 243-258.

Arnold, J.G., Allen, P.M., 1999. Automated methods for estimating baseflow and ground water recharge from streamflow records. J. Am. Water Resour. Assoc. 35 (2), 411-424.

Arnold, J.G., Fohrer, N., 2005. SWAT 2000: current capabilities and research opportunities in applied watershed modeling. Hydrol. Process 19 (3), 563-572.

Arnold, J.G., Williams, J.R., Srinivasan, R., King, K.W., Griggs, R.H., 1994. SWAT: soil water assessment tool. U. S. Department of Agriculture, Agricultural Research Service, Grassland, Soil and Water Research Laboratory, Temple, TX.

Bedient, P., Flores, A., Johnson, S., Pappas, P., 1985. Floodplain storage and land-use analysis at the Woodlands, Texas. Water Resour. Bull. 21 (4), 543-551.

Earls, J., Dixon, B., 2005. A comparative study of the effects of input resolution on the SWAT model. WIT Trans. Ecol. Environ. 12, 213-222.

Echols, S., 2008. Split-flow theory: stormwater design to emulate natural landscapes. Landscape Urban Plan 85 (3-4), 205-214.

Ellis, J.B., Marsalek, J., 1996. Overview of urban drainage: environmental impacts and concerns, means of mitigation and implementation policies. J. Hydraul. Res. 34 (6), 723-731.

EPA Spatial Data Library. U.S. Environmental Protection Agency. Retrieved from http://www.epa.gov/waterscience/basins/.

Ferguson, B.K., 1995. Storm-water infiltration for peak-flow control. J. Irrig. Drain E-ASCE 121 (6), 463-466.

Ferguson, B.K., 1998. Introduction to Stormwater. John Wiley and Sons, New York.

Forsyth, A., 2002. Planning lessons from three US new towns of the 1960s and 1970s-Irvine, Columbia, and The Woodlands. J. Am. Plann. Assoc. 68 (4), 387-415.

Galatas, R., Barlow, J., 2004. The Woodlands: The Inside Story of Creating a Better Hometown. Urban Land Institute, Washington, DC.

Girling, C., Helphand, K.I., 1994. Yard, Street, Park: The Design of Suburban Open Space. John Wiley and Sons, New York.

Girling, C., Kellett, R., 2005. Skinny Streets and Green Neighborhoods: Design for Environment and Community. Island Press, Washington, DC.

Hammer, T.R., 1972. Stream channel enlargement due to urbanization. Water Resour. Res. 8 (6), 1530-1540.

Hann, C.T., Barfield, B.J., Hayes, J.C., 1994. Design Hydrology and Sedimentology for Small Catchments. Academic Press, San Diego.

Haut, R., 2006. Environmental action plan: The Woodlands, Texas. Retrieved from: http://files.harc.edu/Documents/Announcements/2007/Woodands EnvironmentalActionPlan.pdf.

Homer, C., Huang, C., Yang, L., Wylie, B., Coan, M., 2004. Development of a 2001 National Landcover Database for the United States. Photogramm. Eng. Rem. S. 70 (7), 829-840.

Jensen, J.R., 2000. Remote Sensing of the Environment: An Earth Resource Perspective. Prentice Hall, New Jersey.

Kim, J., Ellis, C.D., 2009. Determining the effects of local development regulations on landscape structure: Comparison of The Woodlands and North Houston, TX Landscape Urban Plan 92, 293-303.

Madere, M., 2008. Tropical weather: The Woodlands archives (Houston Chronicle). Retrieved from: http://blogs.chron.com/hurricanes/the_woodlands/.

McHarg, I.L., 1996. A Quest for Life: An Autobiography. John Wiley and Sons, New York.

McHarg, I.L., Sutton, J., 1975. Ecological plumbing for the Texas coastal plain: The Woodlands New Town Experiment. Landscape Archit. 65 (1), 80-90.

Miller, S.N., Semmens, D.J., Goodrich, D.C., Hernandez, M., Miller, R.C., Kepner, W.G., et al., 2007. The automated geospatial watershed assessment tool. Environ. Modell. Softw. 22 (3), 365-377.
Morgan, G., King, J., 1987. The Woodlands: New Community Development 1964-1983. Texas A\&M University Press, TX.

Nash, J., Sutcliffe, J., 1970. River flow forecasting through conceptual models part I-A discussion of principles. J. Hydrol. 10 (3), 282-290.

National Climatic Data Center (NCDC). Retrieved from: http://www.ncdc.noaa.gov/oa/ncdc.html.

National Hydrography Dataset (NHD). Retrieved from: http://nhd.usgs.gov.

National Oceanic and Atmospheric Administration (NOAA) Coastal Services Center. Retrieved from: http://www.csc.noaa.gov/crs/lca/gulfcoast.html.

National Oceanic and Atmospheric Administration (NOAA), 2000. National Weather Service Storm Data and Unusual Weather Phenomena. Retrieved from: www.srh.noaa.gov/hgx/severe/2000/apr00hgx.pdf.

Natural Resources Conservation Service (NRCS). Soil Survey Geographic (SSURGO) Database. Retrieved from: http://soils.usda.gov/survey/geography/ssurgo/.

Paul, M.J., Meyer, J.L., 2001. Streams in the urban landscape. Annu. Rev. Ecol. Syst. 32, 333-365.

Perez-Pedini, C., Limbrunner, J.F., Vogel, R.M., 2005. Optimal location of infiltrationbased best management practices for storm water management. J. Water Res. Pl-ASCE 131 (6), 441-448.

Prince George's County, Maryland, Department of Environmental Resources, 1999 Low-Impact Development Design Strategies: An Integrated Design Approach. Washington, DC: U.S. Environmental Protection Agency. Document No. EPA 841B-00-003.

Rogers, G.O., DeFee, B.B., 2005. Long-term impact of development on a watershed: early indicators of future problems. Landscape Urban Plan 73, 215-233.

Schueler, T.R., 1994. The importance of imperviousness. Watershed Protec. Techniq. $1,100-111$.

Shearer, A.W., 2005. Approaching scenario-based studies: three perceptions about the future and considerations for landscape planning. Environ. Plann. B 32, 67-87.

Smith, R.E., Goodrich, D.C., Woolhiser, D.A. and Unkrich, C.L., 1995. KINEROS-a kinematic runoff and erosion model. In: Singh, V.P. (Ed.), Computer Models of Watershed Hydrology. Water Resources Publications, Highlands Ranch, CO, pp. 697-732.

Soil Conservation Service, 1972. Soil survey of Montgomery County, Texas. U.S. Government Printing Office, Washington, DC.

Soil Conservation Service, 1986. Urban hydrology for small watersheds, Technical release No. 55. Soil Conservation Service, U.S. Department of Agriculture Washington, DC.

Spirn, A.W., 1984. The Granite Garden: Urban Nature and Human Design. Basic Books, New York.

Srinivasan, R., Arnold, J.G., 1994. Integration of a basin-scale water-quality model with GIS. Water Resour. Bull. 30 (3), 453-462.

Stehman, S.V., Wickham, J.D., Smith, J.H., Yang, L., 2003. Thematic accuracy of the 1992 national land-cover data for the eastern United States: statistical methodology and regional results. Remote Sens. Environ. 86, 500-516.

The Woodlands Development Company, 2007. The Woodlands, Texas Demographics, January 1, 2007. The Woodlands Development Company.

U.S. Department of Agriculture (USDA), 2002. National Soil Survey Handbook. Natural Resources Conservation Service (NRCS), Title 430-VI.

U.S. Environmental Protection Agency (USEPA), 2000. Low Impact Development (LID)-A Literature Review. EPA-841-B-00-005.

U.S. Geological Survey (USGS) National Map Seamless Data Distribution System. Retrieved from: http://seamless.usgs.gov/.

Van Liew, M.W., Garbrecht, J., 2003. Hydrologic simulation of the Little Washita River experimental watershed using SWAT. J. Am. Water. Resour. Assoc. 39 (2), 413-426.

Wolter, P.T., Johnston, C.A., Niemi, G.J., 2006. Land use land cover change in the U.S. Great Lakes Basin 1992 to 2001. J. Great Lakes Res. 32, 607-628.

Xiang, W.N., Clarke, K.C., 2003. The use of scenarios in land-use planning. Environ. Plann. B 30, 885-909.

Yang, L., Huang, C., Homer, C., Wylie, B., Coan, M., 2002. An approach for mapping large-area impervious surfaces: synergistic use of Landsat $7 \mathrm{ETM}+$ and high spatial resolution imagery. Can. J. Remote Sens. 29 (2), 230-240.

Yang, B., Li, M.-H., 2010. Ecological engineering in a new town development: drainage design in The Woodlands, Texas. Ecol. Eng. doi:10.1016/j.ecoleng.2010.07.002.

Bo Yang is an Assistant Professor in the Department of Landscape Architecture and Environmental Planning at Utah State University. Dr. Yang received his Ph.D. in Urban and Regional Science (2009) and Master of Landscape Architecture (2009) from Texas A\&M University, Master of Architecture (2004) and Bachelor of Architecture (2002) from Huazhong University of Science \& Technology in China. His areas of interest are environmental planning and technology, stormwater management community planning and design, water related ordinances, and landscape history and theory in China and East Asia.

Ming-Han Li is an Associate Professor in the Department of Landscape Architecture and Urban Planning at Texas A\&M University. He is also an Associate Research Engineer with Texas Transportation Institute. Dr. Li received his Ph.D. in Urban and Regional Science (2002) and Master of Landscape Architecture (1998) from Texas A\&M University, M.S. in Civil Engineering from UT, Austin (1995) and B.S. in Agricultural Engineering from National Taiwan University (1990). His research experience is in stormwater management, bioretention, soil erosion control and roadside vegetation management. Dr. Li is a Professional Engineer and a registered Landscape Architect in Texas. 